\title{
Birds of Different Feathers Cooperate Together: No Evidence for Altruism Homophily in Networks
}

\author{
Brent Simpson, ${ }^{a}$ Matthew Brashears, ${ }^{b}$ Eric Gladstone, ${ }^{b}$ Ashley Harrell ${ }^{a}$ \\ a) University of South Carolina, (b) Cornell University
}

\begin{abstract}
Many evolutionary models of cooperation assume that altruists possess telltale signs of disposition that they use to find and selectively associate with each other. Prior research finds that people can detect these signs of altruism in strangers, but we do not yet know whether this results in altruism homophily. We argue that dispositions should matter less in repeated interactions, where behavior is based on reciprocity. As a consequence, we should not expect people to have accurate insight into the dispositions (egoism vs. altruism) of their friends, nor should we expect these relations to be characterized by altruism homophily. Three studies, employing diverse methodologies and measures, find no evidence of altruism homophily. Moreover, we find that people have poor insight into their friends' altruism. We discuss the implications of these findings for the emergence of altruism and the role of embedded interactions in sustaining human cooperation.
\end{abstract}

Keywords: relations; friends; altruism; prosocial behavior; trust; trustworthiness

Editor(s): Jesper Sørensen, Gabriel Rossman; Received: September 4, 2014; Accepted: October 11, 2014; Published: December 22, 2014

Citation: Simpson, Brent, Matthew Brashears, Eric Gladstone, and Ashley Harrell. 2014. "Birds of Different Feathers Cooperate Together: No Evidence for Altruism Homophily in Networks." Sociological Science 1: 542-564. Dol: 10.15195/v1.a30

Copyright: (C) 2014 Simpson, Brashears, Gladstone, and Harrell. This open-access article has been published and distributed under a Creative Commons Attribution License, which allows unrestricted use, distribution and reproduction, in any form, as long as the original author and source have been credited. (c) (i)

How does altruism persist in the face of in1 centives to exploit it? This question has received increased attention with growing evidence of heterogeneity in altruism, or other-regarding preferences, in humans (van Lange et al. 1997; Fehr and Gintis 2007; Simpson and Willer 2008). One answer from evolutionary models of cooperation is that altruists (who possess other-regarding preferences and act prosocially even in the absence of strategic incentives) possess telltale signs of character that identify them as altruists to prospective friends and exchange partners. Egoists (who are less apt to act prosocially in the absence of reputational or other strategic incentives) lack these characteristics and are avoided. As a result, we should expect social networks to exhibit altruism homophily, with altruists sorting together and reaping benefits from social cooperation, leaving egoists to either pair up together, or go it alone (Wilson and Dugatkin 1997; Frank 1988; Macy and Skvoretz 1998; Sober and Wilson 1998; see also Rand and Nowak 2013).

There is evidence that people can distinguish altruists from egoists, but it derives almost en- tirely from studies examining whether people can predict the prosociality of strangers in one-off interactions (e.g., Frank, Gilovich, and Regan 1993; Brown, Palameta, and Moore 2003; Yamagishi et al. 2003; Oda et al. 2009; Fetchenhauer, Groothuis, and Pradel 2010; Feinberg, Willer, and Keltner 2012). As a result, there is scant evidence for altruism homophily, or the tendency for altruists to be friends with each other at higher than chance levels. Thus, while people are able to read telltale signs of others' dispositions with better than chance accuracy, we do not know whether this ability plays a role in relationship formation. This paper draws on theories of reciprocity (Gouldner 1960; Trivers 1971; Axelrod 1984) to argue that we should not expect altruism homophily.

In addition to altruism homophily, we also address whether people have accurate insight into their friends' dispositions. On one hand, the motivation and ability to read telltale signs is of paramount importance to altruism homophily hypotheses, and relationship formation and continuation should be largely based on assessment of a 
prospective partner or friend's disposition. Thus, friends should be able to predict each other's prosociality at a better than chance level. From a reciprocity perspective, on the other hand, the "shadow of the future" that characterizes friendships implies that both egoists and altruists will tend to act prosocially toward their friends. As a result, we are likely to have limited insight into the extent to which our friends are altruistic because the structure of the relationship, rather than individual dispositions, acts to guarantee their benevolence.

Addressing these competing predictions is important for a number of reasons. Most broadly, many evolutionary models of altruism, or otherregarding behavior, hinge on humans' ability to read telltale signs of disposition and to form friendships based on those abilities. But while prior work suggests that people can read these signs, we don't know that these abilities lead to altruism homophily. If the ability to discern dispositions does not lead altruists to selectively exclude egoists from productive ongoing relationships, it is less clear how the ability to read dispositions can account for altruism homophily and thus the emergence and persistence of altruism.

Further, altruism homophily approaches suggest that relationships between altruists will produce more value than those between egoists, whereas reciprocity approaches suggest that benefits derive from the fact that two individuals are connected, rather than from the combinations of their dispositions. Thus, beyond shedding light on evolutionary explanations of altruism, a better understanding of altruism homophily should yield clearer insight into the costs and benefits of relationships. An investigation of the social processes underlying the formation of cooperative relationships thus has implications both at the micro level of dyadic interaction and the macro level of societal integration.

Finally, homophily, or the tendency for individuals to associate with those like themselves (Lazarsfeld and Merton 1954), is one of the most robust of all social science findings (e.g., McPherson et al. 2001; Smith et al. 2014). Homophily largely depends on the presence of similar others in foci (Feld 1981) frequented by the individual, but some doubtless derives from preferences for associating with those like oneself (e.g., Huston and Levinger 1978). However, research to date has assumed that individuals prefer to associate with those who have similar knowledge or cultural tastes (e.g., Carley 1991; Mayhew et al. 1995). Here we expand the literature on homophily by asking a more fundamental question: Do humans prefer to associate with those whose basic values (e.g., altruism and egoism) are like their own?

In what follows, we introduce necessary terminology and briefly review arguments linking the ability to read telltale signs of character with altruism homophily and thus the emergence of altruism and cooperation. We then argue why we should not necessarily expect detection abilities to translate into altruism homophily and extend these arguments to the question of whether people have knowledge of their friends' dispositions. We then introduce three studies to test the homophily predictions, including a Respondent Driven Sampling survey of ties between students at a large public university (Study 1), a study of friendship ties within a sorority chapter (Study 2 ), and a laboratory experiment (Study 3 ). The laboratory experiment also allows us to test predictions about people's knowledge of their friends' altruism. Across all studies, using a variety of data and analytic techniques, we find virtually no evidence of altruism homophily. We also find that friends have surprisingly limited insight into each other's dispositional altruism. Together, results from the three studies offer consistent support for our argument that there is little reason to expect altruism homophily in networks.

\section{Altruism and Telltale Signs of Disposition}

We define prosocial behavior as any behavior that benefits another person, regardless of the underlying motivation for the act (Piliavin and Charng 1990). Thus, prosocial behavior is an outcome, whereas altruism and egoism are motivational precursors to behavior. Recent research has established strong behavioral (e.g,. van Lange 1999; Simpson and Willer 2008) and neurological (Emonds et al. 2011) evidence for the existence of heterogeneous social preferences, as well as egoists' and altruists' divergent responses to various incentives for prosocial behavior.

The notion that altruists possess telltale signs that allow them to identify each other informs 
much of the work on selective assortation (Eshel and Cavalli-Sforza 1982; Wilson and Dugatkin 1997; Sober and Wilson 1998; see also Macy and Skvoretz 1998), but it has arguably received its most extensive treatment in Frank's (1988) commitment model. Frank argues that individual differences in moral sentiments, such as sympathy, compel individual differences in moral behavior. If these moral sentiments are revealed to others by telltale signs of character, such as emotional displays, the argument continues, altruists will be preferentially chosen as exchange partners. Because altruists will seek to associate with others who also display signs of altruism and avoid those who do not, altruistic types will tend to pair up with one another. Egoists are thus left to go it alone (and miss out on the benefits of social cooperation) or make do with one another. Such a process allows altruism to compete successfully with egoism.

If telltale signs of disposition create an advantage for altruists, they create an even greater benefit to egoists who are able to fake the signal and reap the benefits of having altruistic partners without paying the costs of altruism (Trivers 1971; Dawkins 1976; Macy and Skvoretz 1998). While acknowledging the potential for egoists to feign altruists' signs, Frank argues that the emotional cues are costly and difficult to fake for those who do not actually experience the underlying emotion. The incentive for egoists to mimic altruism, and the concomitant need for altruists to be wary of mimics, is predicted to result in an equilibrium mix of egoists skilled at deception and vigilant altruists continually on the lookout for wolves in sheep's clothing (Frank 1988).

The empirical evidence supports the ability of people to read telltale signs of dispositional altruism. Frank et al. (1993) found that participants in a laboratory experiment could predict cooperation and defection in interaction partners at better than chance levels (see also Brosig 2002). Other work shows that people can distinguish altruists from egoists based on discussion of unrelated issues (Yamagishi et al. 1999), brief video exposure (Brown, Palameta, and Moore 2003; Oda et al. 2009; Fetchenhauer et al. 2010; Feinberg, Willer, and Keltner 2012) or even a photograph (Yamagishi et al. 2003; Verplaetse et al. 2007).

sociological science | www.sociologicalscience.com
This prior work shows that people can read telltale signs of disposition, but it does not tell us whether, as a result, they form relationships characterized by dispositional homophily. To our knowledge, only two studies have addressed whether altruists attract and associate with each other. First, Sheldon et al. (2000) looked at the "prosocial values" of friends and found a marginally significant correlation. However, it is not clear that their measure of prosocial values was related to altruism or prosociality as the terms are used in the literature 1

A second study by Pradel and colleagues (2009) measured generosity in six relatively small secondary school classrooms (14 to 29 students) using a "modified dictator game." Each student was asked to imagine that they had been given a monetary endowment and to decide how much of the endowment to pass on to an unspecified classmate. Participants were told that "dictators" and "recipients" would be matched approximately one week later. Pradel and colleagues observed modest correlations between the friends' generosity. Further, a series of follow-up questions found that students were able to predict the generosity of their friends and enemies (but not other classmates) with greater than chance accuracy.

While suggestive, several important issues limit the conclusions we can draw from the Pradel et al. study. First, because students were told that their dictator decision would affect an unspecified member of the class, the measure may have captured the dictator's general orientation toward the class as a whole, rather than altruism. Thus, we cannot know whether the method tracked altruism homophily or whether those with similar sentiments toward the class were simply more likely to be friends 2 Alternatively, if the

\footnotetext{
${ }^{1}$ Although presented as a test of whether altruists sort together, Sheldon and colleagues measured values using an Aspirations Index that distinguished intrinsic values (e.g., "I will know and accept who I really am") and extrinsic values ("I will have people comment often about how attractive I look"). Because it is not clear to what extent, if at all, these values overlap with dispositional altruism or egoism, it is not clear what the Sheldon et al. findings tell us about altruism homophily.

${ }^{2}$ For instance, Harbaugh and Krause (2000) found that the greater proportion of a child's education that had been spent among current classmates, the more generous she or he was to the rest of the class. To the extent that those who have been at a given school longer are more apt to be friends, this could result in the appearance of altruism homophily.
} 
measure tracked generosity to a person, rather than orientation to the class as a whole, it isn't clear to what extent it tracked generosity toward a close other versus a distant other. This would depend, among other things, on the assumptions the dictator made about who would ultimately benefit from her decision.

Second, as the authors note (p. 109), it isn't clear to what extent the findings were driven by generosity versus reputation management: "Our experimental setting, in which we seated participants in a circle to enable them to link classmates with subject numbers, might have created a context that students perceived as partly public... Observed altruistic behavior ... therefore, cannot unconditionally be interpreted as 'pure' altruism in the sense that it was independent of reputation management efforts."

\section{Reciprocity and Social Relations}

Whereas the arguments just reviewed assume that prosociality emerges out of individuals' dispositions, reciprocity approaches (Gouldner 1960; Trivers 1971; Axelrod 1984) view prosociality and cooperation as stemming from relational inducements. We build on this perspective to address why individual differences in dispositional altruism need not factor into longterm social relations and thus why we should not expect to observe altruism homophily.

In a reciprocity approach, not only is cooperation the most effective way for altruists to realize their goals, assuming others cooperate; egoists can also maximize their self-interest in longterm social relations by engaging in tit-fortat exchanges, or "reciprocal altruism" (Kollock 1998; van Lange et al. 2011). As a result, dispositional differences that have powerful effects on behavior in interactions with strangers have limited impact in repeated interactions.

Empirical evidence supports the prediction that the behaviors of egoists and altruists, while highly divergent in one-off interactions, tend to matter less in longer term relations (e.g., Kuhlman and Marshello 1975; Parks and Rumble 2001). Even the possibility that an interaction may con- tinue can eliminate the otherwise strong behavioral differences we observe between egoists and altruists in one-off interactions (van Lange et al. 2011). Further, egoists and altruists show no difference in willingness to sacrifice for their romantic partners (e.g., van Lange et al. 1997).

From the perspective of reciprocity approaches, treatment of longterm partners is more influenced by structures of interdependence in a given relation (e.g., the dependence of each person on the other and the availability of suitable alternatives) than either partner's dispositional altruism or egoism (see also Kelley and Thibaut 1978; Rusbult and van Lange 2003). Repeated interactions lead to a convergence of strategies within those relations that make altruists and egoists behaviorally indistinguishable.

While prior work establishes that the mere possibility of repeated interaction moderates the impact of dispositions on behavior, we do not know whether people actually anticipate this effect. If people do not intuit that ongoing relationships attenuate the effects of others' dispositions, we would expect people to attach similar value to information about a potential partner's disposition whether they anticipated one-off or repeated interactions. As a consequence, we would expect to observe a tendency towards altruism homophily even though dispositions matter little once relations are established.

However, we expect that people understand that relationships and repeated interactions moderate the impact of dispositions. If this is the case, they will invest less in gaining information about others' character when they expect repeated versus one-off interactions. Such a pattern would provide a stronger theoretical foundation for predicting the absence of altruism homophily. In a series of ancillary experiments, available upon request from the first author, we found empirical evidence for precisely this pattern.

To summarize, individual differences in altruism that emerge in one-off interactions with strangers lose their predictive power in repeated interactions. Given that social relations such as friendships are repeated interactions, there is no reason to expect altruism homophily. This stands in marked contrast to the evolutionary models described earlier that explain the emergence of altruism and cooperation via altruism homophily. 


\section{Perceived Altruism Homophily}

The ability and motivation to read telltale signs of disposition is fundamental to altruism homophily approaches. Further, these approaches suggest that it is precisely in longterm relations such as friendships that we should observe evidence that people have insight into their partners' disposition (e.g., Frank 2005), since these are the relationships that matter most and where there would be the greatest opportunity to detect subtle telltale signs. But here we instead extend our application of reciprocity theories to explain why friends' altruism should be relatively inaccessible.

People often have limited information about a friend's prosociality outside the friendship. What information is available may be distorted by the friend's accounts (Scott and Lyman 1968) or other impression management strategies. Additionally, the fact that both altruism and egoism (through the possibility of reputational gains, for instance) can motivate prosociality allows for varied interpretations of a single prosocial act by the friend. Prior work suggests that altruistic versus egoistic dispositions influence the attributions people make about others' prosociality (see Simpson and Willer 2008), such that altruists and egoists project their own values and motives onto others' behaviors (Orbell and Dawes 1993). This implies that altruism homophily will be more perceived than real, as people interpret friends' behaviors in light of their own dispositions. That friendships will be characterized by perceived dispositional homophily is in line with the broader homophily literature, which shows that people tend to think that their friends are more similar to them with respect to attitudes and beliefs than is actually the case (McPherson, Smith-Lovin, and Cook 2001; Goel, Mason, and Watts 2010).

\section{Hypotheses and Overview of Studies}

Our first empirical objective is to assess whether friendships will exhibit altruism homophily (as suggested by evolutionary models of altruism reviewed above) or whether, as we expect, friendships will be random with respect to dispositions. We test these competing predictions in two network surveys (Studies 1 and 2) and a laboratory experiment (Study 3). Second, we assess competing predictions about whether people can intuit their friends' prosociality. Altruism homophily arguments predict that friends will have insight into the extent to which their friends will act prosocially toward strangers. Our arguments, however, lead us to expect that friends will be poor at predicting each other's prosociality toward strangers. Further, we expect that this inaccuracy will be driven in part by perceived altruism homophily i.e., the tendency to (inaccurately) perceive one's friend as being as altruistic or egoistic as oneself. We test these predictions in the laboratory experiment using several measures of prosociality.

\section{Study 1: Homophily in a Respondent Driven Sample}

Our first test uses data from a Respondent Driven Sampling (RDS) study. RDS samples begin with a modest number of initial respondents who recruit the second wave of respondents through their network connections, and so on for subsequent waves. Given a sufficient number of recruitment waves, the characteristics of an RDS sample converge on those of a random sample, thereby permitting statistical inference (Heckathorn 2007).

Respondents were students at a large southeastern university and could earn up to $\$ 25$ for completing a web-based survey and recruiting as many as three other respondents. The survey was part of a larger project (Wejnert 2010) and included basic demographic questions, a standard measure of dispositional altruism, and questions about student life (e.g., whether the respondent was a member of a Greek organization, lived on or off campus, etc.) and personal networks.

\section{Procedures}

The sample began with nine respondents who received an email explaining the purpose of the project and details on compensation. If a respondent agreed to participate, he or she clicked on a link to the online survey. After completing the survey, the respondent received three recruitment emails that they were asked to forward to three potential recruits who were students at the university and with whom they had regular contact. These later recruits followed the same process 
as the initial seeds. Each participant was paid $\$ 10$ for completing the 20-minute survey and an additional $\$ 5$ for each recruit who did so, for a total individual maximum compensation of $\$ 25$ and a mean of $\$ 15$.

\section{Altruism Measure}

We assessed altruism using the standard nineitem measure of social value orientation (SVO), arguably the most widely used survey measure of dispositional altruism (van Lange 1999; Feinberg et al. 2012). Social value orientations are stable preferences for how outcomes are distributed between self and others (Messick and McClintock 1968). Our measure presented respondents with a series of nine decomposed games, each consisting of three different distributions of points for self and another (unidentified) person. The other was presented to respondents as "someone you do not know and that you will not knowingly meet in the future." Individualist choices maximize payoffs to self, without regard to the other's payoff; competitive choices maximize the difference between the payoff to self and other; altruistic choices maximize the aggregate payoff to self and other and minimize inequality in payoffs. Previous research has established the temporal stability (van Lange 1999) and overall predictive power (Liebrand 1986) of such measures for a wide range of behaviors, including contributions to real world charities (van Lange et al. 2007).

Following prior work, we classified participants as a given SVO (altruist, individualist, or competitor) only if their responses to at least six of the survey items were consistent with that orientation. Most prior work also collapses responses from individualists and competitors into one "egoist" category. As analyses using a greater level of specificity did not affect our conclusions, we follow this prior work. Thus, our key comparison centers on the distinction between altruists and egoists.

\section{Study 1 Results}

A total of 310 respondents (145 females) participated in Study 1. Among these, 147 were classified as altruists and 126 egoists (84 individualists and 42 competitors). The remaining (46) did not make at least six choices consistent with a given SVO and thus could not be classified.

\section{Homophily}

We outline the results of four logistic regression models. The first two models predict whether the recruiter is an altruist or an egoist as a function of the respondent's SVO. These models allow us to determine whether there is a general preference for association with altruists, as we might expect, as well as permit us to detect dispositional homophily. The third model predicts whether the recruiter is a female based on the respondent's sex, permitting us to detect gender homophily. Investigation of gender homophily allows us to assess whether our methods track homophily where it exists ${ }^{3}$ Finally, we might expect that relations characterized by more frequent interactions or closer ties would be more apt to exhibit altruism homophily than weaker relations (Frank 2005; Pradel et al. 2009). The fourth model thus addresses whether tie strength impacts dispositional homophily and uses a new dependent variable that distinguishes SVO-homogeneous dyads from SVO-heterogeneous dyads without regard to the SVO of the recruiter.

All four models are given in Table 1. The first model predicts whether a respondent's friend is an altruist, the second predicts whether a respondent's friend is an egoist, the third predicts whether the respondent's friend is female, and the fourth predicts whether the respondent and his or her recruiter have dispositional homophily. Given our focus on homophily, in each of the first three models the main independent variable is a dummy variable indicating whether the respondent is an altruist (model 1), an egoist (model 2 ), or female (model 3). The fourth model contains two additional dummy variables measuring tie strength: whether the respondent reported interacting with the recruiter at least once per

\footnotetext{
${ }^{3}$ Specifically, if we do not observe dispositional homophily or gender homophily, it will suggest that our data may be compromised, given that gender homophily is a robust phenomenon in social networks (McPherson et al. 2001; Smith et al. 2014). If we observe dispositional homophily and gender homophily, it will suggest that friends are more likely than chance to have the same disposition. Finally, if we observe gender homophily but not dispositional homophily, it will suggest that our data are sufficient to identify homophily, but that friends are not more likely than chance to have the same disposition.
} 
Table 1: Logistic Regression Estimates for Models Predicting Altruism Homophily in a Respondent Driven Sample (Study 1)

\begin{tabular}{|c|c|c|c|c|}
\hline & $\begin{array}{l}\text { Altruistic } \\
\text { Friend }\end{array}$ & $\begin{array}{l}\text { Egoistic } \\
\text { Friend }\end{array}$ & $\begin{array}{l}\text { Female } \\
\text { Friend }\end{array}$ & $\begin{array}{c}\text { SVO } \\
\text { Homophily }\end{array}$ \\
\hline Altruistic Respondent & $\begin{array}{c}0.33 \\
(0.27)\end{array}$ & & $\begin{array}{c}-0.12 \\
(0.31)\end{array}$ & \\
\hline Egoistic Respondent & & $\begin{array}{c}0.41 \\
(0.27)\end{array}$ & & $\begin{array}{c}-0.32 \\
(0.38)\end{array}$ \\
\hline Unclassified Respondent & $\begin{array}{c}-0.11 \\
(0.36)\end{array}$ & $\begin{array}{c}0.37 \\
(0.32)\end{array}$ & $\begin{array}{r}-0.50 \\
(0.39)\end{array}$ & $\begin{array}{r}-1.98^{\dagger} \\
(0.75)\end{array}$ \\
\hline Altruistic Referrer & & & $\begin{array}{c}-0.01 \\
(0.41)\end{array}$ & \\
\hline Egoistic Referrer & & & & $\begin{array}{c}-0.32 \\
(0.27)\end{array}$ \\
\hline Unclassified Referrer & & & $\begin{array}{l}0.15 \\
(0.65)\end{array}$ & $\begin{array}{r}-1.63^{*} \\
(0.78)\end{array}$ \\
\hline Female Respondent & $\begin{array}{c}-0.25 \\
(0.35)\end{array}$ & $\begin{array}{c}0.37 \\
(0.34)\end{array}$ & $\begin{array}{r}2.01^{\dagger} \\
(0.30)\end{array}$ & $\begin{array}{c}-0.22 \\
(0.33)\end{array}$ \\
\hline Female Referrer & $\begin{array}{c}-0.23 \\
(0.53)\end{array}$ & $\begin{array}{c}0.18 \\
(0.54)\end{array}$ & & $\begin{array}{c}-0.22 \\
(0.42)\end{array}$ \\
\hline Female Respondent $\times$ Female Referrer & $\begin{array}{c}0.33 \\
(0.61)\end{array}$ & $\begin{array}{c}-0.36 \\
(0.61)\end{array}$ & & $\begin{array}{c}0.20 \\
(0.53)\end{array}$ \\
\hline Interacts Weekly or More & & & & $\begin{array}{c}0.16 \\
(0.49)\end{array}$ \\
\hline Discusses Important Matters & & & & $\begin{array}{c}0.11 \\
(0.32)\end{array}$ \\
\hline Constant & $\begin{array}{c}-0.11 \\
(0.30)\end{array}$ & $\begin{array}{r}-0.73^{*} \\
(0.29)\end{array}$ & $\begin{array}{r}-1.36^{\dagger} \\
(0.42)\end{array}$ & $\begin{array}{c}0.28 \\
(0.49)\end{array}$ \\
\hline $\mathrm{N}$ & 310 & 310 & 310 & 307 \\
\hline
\end{tabular}

week, and whether the respondent reported discussing important matters with the recruiter. In all models we control for homophily of other types (models 1, 2, and 4 control for gender homophily; model 3 controls for altruism homophily). We ran other models with additional control variables, including controls for tie strength in models 1 , 2 , and 3 . The alternative models yielded substantively identical conclusions to those reported below. Because the same individual could recruit up to three others, dyads are not statistically independent, and we adjust our models for this clustering of observations on recruiters. (Omitting this adjustment does not alter our results.)

On the whole, Table 1 shows no evidence of dispositional homophily. First, as shown in model 1 , we find that altruistic respondents are no more likely to have an altruistic friend than are egoists.
Likewise, egoists are no more likely to be associated with egoists than altruists (model 2). In combination, these two models fail to show evidence for dispositional homophily. In contrast, we observe substantial homophily by gender (model 3 ). As expected, female respondents are more likely to be recruited by female friends than are male respondents. Since respondents are recruited via existing social network ties, this result indicates that interpersonal ties do exhibit homophily by gender, as we would expect from prior work, but do not exhibit homophily by disposition. Finally, model 4 shows that stronger ties are no more likely than weaker ties to exhibit dispositional homophily. In short, these data do not support the altruism homophily hypothesis.

In estimating the logit models, we treated the RDS data as though they were derived from 
a standard survey and did not weight to adjust for the non-random nature of respondent recruitment, although we did adjust for the clustering of observations. This decision stems in part from the fact that multivariate models rely on correlations between variables that are rarely impacted by weighting procedures. Thus, including weights would not alter our conclusions (Heckathorn 2007). As a check, we conducted ancillary analyses employing methods specific to RDS that incorporate corrections for non-random selection of respondents (Heckathorn 2007; Wejnert 2010). These models, available upon request, yielded the same conclusions given above. The ancillary analyses indicate the presence of homophily by gender, age, and class, as well as on a various aspects of university life, such as membership in Greek organizations, living onor off-campus, and participation in intramural sports. But they do not suggest any evidence of dispositional homophily.

\section{Discussion of Study 1}

The results of the RDS study show no evidence of altruism homophily. Study 1, however, relied upon a sample drawn from an entire university population. It is possible that the emergence of altruism homophily may require a high level of mutual interaction so that altruists and egoists can be more easily identified. It is also possible that altruism homophily is more apt to emerge in groups that are more homogeneous on key sociodemographic dimensions. For instance, people might first sort on characteristics such as race, ethnicity, or religion and only then invest resources in discerning telltale signs of altruism and forming social relations based on these insights. Given these questions, Study 2 investigates altruism homophily in a bounded homogeneous group where the conditions of repeated mutual interactions between people of similar socioeconomic profiles can be met.

\section{Study 2: Homophily in a Sorority Chapter}

Respondents in Study 2 were members of a traditional sorority chapter (with 247 members) at the same university sampled in Study 1. The chapter is homogeneous: all members are female, they are similar in age and socioeconomic background, and the vast majority are white. Members received an email, sent with permission over the chapter listserv, with a link to an online survey. The survey included the measure of altruism used in Study 1 and a number of network measures.

\section{Altruism and Association Measures}

In addition to completing the altruism measure, respondents viewed a complete chapter roster and were asked to select the person they considered their best friend in the sorority. We also used several other measures that have been used in prior work on friendship and close relations (e.g., Paxton and Moody 2003): each respondent was asked to select "up to five [chapter] sisters with whom you regularly discuss important matters;" "up to five sisters with whom you regularly go out socially;" and "up to five sisters in whom you regularly confide and/or go to for advice."

In addition to the measures of social ties, respondents were asked to indicate "up to five sisters who you feel sacrifice most on behalf of the sorority." Unlike the preceding four measures, this last question does not measure social ties between the respondent and another member of the sorority, but instead functions as a reputational measure. This measure captures whether members of the sorority can identify those who act more prosocially towards the group, whether or not they are more inclined to socialize with them.

Finally, respondents were asked to approximate what percentage of their closest friends were chapter members. This provides a measure of the extent to which the sorority is a closed system. We also collected information on the respondent's pledge (year) group and college major, as well as basic demographic questions, including religious beliefs, political values, and father's and mother's education. The survey took about 25 minutes to complete.

\section{Study 2 Results}

The sample includes 127 members of the sorority, for an approximate 51 percent response rate. Given this low response rate, we treat these data as an ego network sample for purposes of analysis. More complex analyses using exponential random 
graph models (e.g., Lusher, Koskinen, and Robins 2013) produced substantially similar results, but as these models are compromised by the large amount of missing data, we limit discussion to the ego network approach.

Altruists make up 38.6 percent of the sample, and individualists and competitors make up 25.2 percent and 16.5 percent, respectively. This distribution is comparable to Study 1 and to those from prior work (e.g., Simpson and Willer 2008). Again, we group individualists and competitors into one "egoist" category (41.7 percent of the sample). Those who did not give at least six responses consistent with either altruism or egoism make up 19.7 percent of the sample.

In ancillary analyses, we looked at the number of others chosen by each sorority member (outdegree) and the number of times they were chosen by others (indegree) in each of the five relations (important matters, social activities, advice, sacrifice, and best friend). These analyses, available upon request, revealed that altruists and egoists had similar outdegrees and similar indegrees across all measures with one exception: as discussed below, altruists were somewhat more likely than egoists to be selected by other members as sacrificing on behalf of the chapter. We also assessed whether there was a general preference for altruists in any of the relationship measures, including whether respondents of a given disposition are more likely to have large numbers of altruistic friends. These analyses showed that altruists count approximately the same number of altruists among their friends as do egoists.

\section{Is There Dispositional Homophily?}

We now turn to whether relations in the sorority show dispositional homophily. Table 2 gives a series of five regression models, one for each of the five relation types. Models 1-4 take as their dependent variables a count of the number of nominated individuals with the same disposition as the respondent. Model 5 estimates the probability that the respondent and her best friend share the same disposition.

Models 1-4 include two independent variables (altruist and unclassified) and two control variables (number of names given for that relation and percent of friends in sorority). The two independent variables are dummies, one of which equals one when the respondent is an altruist and the other which equals one when the respondent has an unclassifiable SVO. Thus, egoist is the reference category, and the dummy variables allow us to determine if respondents of a given disposition are more likely to show dispositional homophily. The control variables for these models are the number of names given for each relation and the percentage of all the respondent's friends who derive from the sorority. The former controls for the opportunity to be named by the respondent (i.e., the more alters a respondent reports, the more likely it is that some will share an SVO with the respondent). The latter controls for the respondent's dependence on the sorority for her social ties.

Model 5, investigating the disposition of a respondent's best friend in the sorority, includes the same independent variables. The control variable (number of names given) is omitted from these models, however, as respondents could only provide a single name. In its place a variable is added indicating whether or not the best friend reciprocates the nomination.

Across the models, the only consistent effect is that the more alters named by the respondent, the more homophilous friends a respondent has. The sole exception to this general trend is for the selection of those who sacrifice most for the sorority (model 4). In this case respondents are not selecting friends but rather are reporting on those whom they perceive to be the largest contributors to the group, and altruists are more likely to be chosen by everyone. This finding suggests that members of the sorority can accurately identify more altruistic members (via contributions to the group), but do not exhibit preferences for associating with them.

Finally, model 5 suggests that altruists may be somewhat more likely to have altruistic best friends. However, this may result from the fact that that there are more altruists than individualists, competitors, or unclassified respondents, which could lead them to show dispositional homophily in random assortment (i.e., due to random chance, altruists are more likely to select another altruist as a best friend). A chi-squared test for independence indicates that once marginal effects are taken into account there is no association between the disposition of the respondent and the disposition of her best friend $(p=0.12)$, sug- 
Table 2: Regression Estimates for Models Predicting Altruism Homophily Across Four Types of Close Relations in a Sorority (Study 2)

\begin{tabular}{|c|c|c|c|c|c|}
\hline & \multicolumn{5}{|c|}{ SVO Homophily } \\
\hline & $\begin{array}{l}\text { Important } \\
\text { Matters }\end{array}$ & $\begin{array}{c}\text { Social } \\
\text { Activities }\end{array}$ & Advice & Sacrifice & $\begin{array}{l}\text { Best } \\
\text { Friend }\end{array}$ \\
\hline Altruist & $\begin{array}{c}-0.17 \\
(0.22)\end{array}$ & $\begin{array}{c}-0.29 \\
(0.19)\end{array}$ & $\begin{array}{c}-0.23 \\
(0.21)\end{array}$ & $\begin{array}{r}1.01^{\dagger} \\
(0.22)\end{array}$ & $\begin{array}{r}1.31^{*} \\
(0.59)\end{array}$ \\
\hline Unclassified & $\begin{array}{r}-0.91^{*} \\
(0.37)\end{array}$ & $\begin{array}{r}-1.08^{\dagger} \\
(0.36)\end{array}$ & $\begin{array}{r}-0.97^{\dagger} \\
(0.35)\end{array}$ & $\begin{array}{c}0.78 \\
(0.42)\end{array}$ & $\begin{array}{c}-1.01 \\
(1.14)\end{array}$ \\
\hline Number Given & $\begin{array}{r}0.44^{\dagger} \\
(0.08)\end{array}$ & $\begin{array}{r}0.51^{\dagger} \\
(0.09)\end{array}$ & $\begin{array}{r}0.46^{\dagger} \\
(0.09)\end{array}$ & $\begin{array}{r}0.55^{\dagger} \\
(0.08)\end{array}$ & \\
\hline Percent Friends in Sorority & $\begin{array}{c}0.00 \\
(0.01)\end{array}$ & $\begin{array}{c}0.00 \\
(0.01)\end{array}$ & $\begin{array}{c}0.00 \\
(0.01)\end{array}$ & $\begin{array}{r}-0.00 \\
(0.01)\end{array}$ & $\begin{array}{c}0.00 \\
(0.01)\end{array}$ \\
\hline Best Friend Reciprocity & & & & & $\begin{array}{c}1.09 \\
(0.59)\end{array}$ \\
\hline Constant & $\begin{array}{r}-1.42^{\dagger} \\
(0.37)\end{array}$ & $\begin{array}{r}-1.58^{\dagger} \\
(0.39)\end{array}$ & $\begin{array}{r}-1.68^{\dagger} \\
(0.39)\end{array}$ & $\begin{array}{r}-2.01^{\dagger} \\
(0.37)\end{array}$ & $\begin{array}{r}-2.45^{\dagger} \\
(0.86)\end{array}$ \\
\hline $\mathrm{N}$ & 127 & 127 & 127 & 127 & 80 \\
\hline Dependent variable & Count & Count & Count & Count & $0 / 1$ \\
\hline Model & Poisson & Poisson & Poisson & Poisson & Logit \\
\hline
\end{tabular}

${ }^{\dagger} p<0.01 ; * p<0.05$.

gesting that the effect in model 5 is simply a result of demographic availability (Blau 1977a).

On the whole, these results suggest that sorority members are able to identify at least some altruists - namely those who sacrifice most for the wellbeing of the sorority as a whole-but display no general tendency to preferentially associate with them. There is, additionally, no evidence that egoists are forced into association with each other as a result of collective exclusion by altruists. We must therefore conclude that the altruism homophily hypothesis is unsupported.

\section{Discussion of Study 2}

Findings from Study 2 are highly consistent with those of Study 1. The two studies converge on the same basic conclusion, but they also share a limitation: both studies used the same measure of altruism. Like other survey measures meant to tap into socially desirable preferences or behaviors, it may be prone to response bias, although recent research suggests this is not the case (Willer et al. 2014). Additional evidence that SVO tracks actual motivational and behavioral differences comes from the Study 2 finding that those who made more altruistic responses were more often listed by their fellow sorority sisters as making greater sacrifices for the group. This result adds to a large body of work demonstrating that social value orientation is a powerful predictor of altruistic behavior in a wide range of settings (see Bogaert, Boone, and Declerck 2008). That said, it was costless for the respondents of Studies 1 and 2 to give altruistic responses to the survey measure. Moreover, given that we used the same measure in both studies, it is possible that the absence of altruism homophily resulted from measurement error. Our next study aims to establish greater confidence in our conclusions by expanding the range of altruism measures to include costly behaviors. Finally, our results thus far do not tell us whether people have poor insight into their friends' dispositions, as we expect, or whether they possess accurate insight but simply do not care about - and thus do not sort on the basis of - altruistic disposition. Study 3 allows us to address this question. 


\section{Study 3:}

\section{Laboratory Experiment}

\section{Pre-Study Survey}

Participants were recruited for the study in exchange for the opportunity to earn money. During recruitment, seed participants were told that they would need to invite a friend to participate with them, and that this friend would also have the opportunity to earn money, but were given no indication of what the experiment was about. Friends were required to have known each other for a minimum of two months.

At least a week before participating, each member of each dyad completed a brief survey about the friendship. As shown in the online supplement, each participant reported how long he or she had known the other and responded to six five-point Likert scale items designed to capture key dimensions of friendship strength, including length of friendship and closeness (Marsden and Campbell 1984).

\section{Laboratory Methods}

Participants were scheduled in groups of ten to sixteen (or five to eight dyads). A total of 106 students (66 females), or 53 dyads, participated. Upon the participants' arrival to the laboratory, a research assistant collected cell phones and other communication devices to ensure that friends could not communicate with each other during the course of the study. Thereafter, each participant was escorted to a private room, where he or she remained for the duration of the study. As participants waited for others to arrive, they signed a consent form and completed the nineitem measure of social values used in Studies 1 and 2. Participants were then given several envelopes, each containing the directions and forms for one of the prosocial behavior measures described below.

A research assistant described the basic experimental instructions: participants were to open the first envelope and work on the task inside. Once they were finished, they were to put the materials back in the envelope and slide the envelope under the door, then proceed to the materials inside the next envelope, and so on, completing the tasks in the order that they were given. Par- ticipants were asked to return their materials by sliding them under the workstation door, rather than handing them to a research assistant, in order to maximize anonymity.

The first envelope contained instructions for the tasks. Specifically, participants were told that the study was about how people make decisions in various situations, and that each task consisted of one "decision scenario." They were told that their decisions, along with the decisions of other participants, would determine their pay for the study. Specifically, they were informed (correctly) that they would be paid for one randomly selected decision-scenario at the end of the study. The instructions further emphasized that they would never be paired with the same participant more than once, that they would never be paired with their friend, and that their decisions would remain completely anonymous. All these points were reemphasized prior to each decision scenario.

To further increase anonymity, participants were informed that decisions and payments would be computed by a research assistant who would have no contact with the participant at any point during the study. After reading these preliminary instructions, participants made decisions in three scenarios, each measuring a distinct form of prosocial behavior: generosity, trust, and trustworthiness. Participants were told that they would not receive any feedback about others' behaviors until the end of the study (and then only with anonymous identifiers).

\section{Measures of Prosociality}

First, we measured generosity in a "dictator game." The dictator game is a situation of unilateral dependence (Kelley and Thibaut 1978) and is the standard behavioral measure of generosity (Hoffman, McCabe, and Smith 1996). Participants were told that the situation would involve two participants: a decider and a receiver ${ }^{4}$ The decider was given $\$ 20$ and had to decide how much (if any) to send to the receiver and how much (if any) to keep for him or herself. The instructions explained that the decider could send anywhere from $\$ 0$ to $\$ 20$. The decider's and receiver's pay-

\footnotetext{
${ }^{4}$ The scenario was not referred to as a dictator game anywhere in the instructions to participants. Nor did we ever use any loaded terms like generosity, altruism, or trust.
} 
ment for this decision-scenario thus depended solely on the decider's generosity.

For the first scenario, all participants were told they would occupy the decider role. Thereafter, participants indicated how much - from $\$ 0$ to $\$ 20$ - they wished to send to the receiver. Participants were subsequently notified that they would be the "receiver" in a second dictator game. Because the dictator game models a situation of unilateral dependence, receivers did not actually make a decision. Rather, in this second scenario, each participant was paired with a participant from the first scenario. Having each participant be a decider in one dictator scenario and receiver in another allowed us to take a behavioral measure of generosity from each participant without using deception (such as by pairing participants with fictitious receivers).

The second and third decisions were, respectively, standard behavioral measures of trust and trustworthiness (Berg, Dickhaut, and McCabe 1995). Specifically, participants made decisions in the trust dilemma, which involves two roles: trustor and trustee. For the trust measure, participants occupied the role of the trustor (referred to in experimental instructions as the "sender"). The instructions explained that both the trustor and the trustee would be allocated $\$ 10$ as a "starting fund." As a trustor, the participant was told that he or she could send any amount of his or her starting fund to the trustee ("returner"). Any amount sent to the trustee would be tripled. (For instance, if the trustor sent all $\$ 10$, the investment would yield $\$ 30$.) The trustee would decide how much of the tripled amount to keep for him or herself and how much to return to the trustor. Return amounts were not tripled. Nor could the trustee send any of his or her starting fund to the trustor. After indicating the amount he or she wished to send to the trustee (our behavioral measure of trust), the participant moved on to the next decision.

For the final behavioral measure, trustworthiness, the instructions briefly reviewed the trust dilemma. Following prior work (e.g., Barrera 2007; Simpson, McGrimmon, and Irwin 2007), we had trustees indicate a return amount for each amount the trustor could potentially send (i.e., "If the Sender sends $\$ 1$, you will receive $\$ 3$. How much of this do you wish to return?" and so on, through "If the Sender sends $\$ 10$, you will receive $\$ 30$. How much of this do you wish to return?"). Analogous to the dictator scenario, we calculated trustee (and trustor) payments by pairing a trustee with a trustor from the second decision scenario.

After completing the behavioral measures of generosity, trust, and trustworthiness, participants moved on to the next phase of the study, during which they were asked to make predictions of their friend's and a random stranger's behaviors on each of these measures.

\section{Predictions of Others' Behaviors}

The instructions for the prediction task explained that the participant would predict other participants' choices in each of the three decision scenarios they had completed. Specifically, they were told that they would be asked to predict their friend's behaviors, as well as the behaviors of another participant whom they did not know. Prior to this phase of the study, participants were unaware that they would be predicting others' behaviors.

Having participants predict the behavior of a stranger created a baseline against which we could measure the participant's perceptions of their friend's prosociality. Whether the participant first made predictions of the friend's or stranger's decisions was randomized. We incentivized predictive accuracy by paying participants a $\$ 2$ bonus for each correct prediction.

After reading a brief refresher of each decision scenario, the participant made a prediction about his or her friend's behavior and a randomly selected stranger's behavior in the dictator game, as trustor in the trust dilemma, and as trustee in the trust dilemma. To reduce the length of the prediction phase for the trustee decisions, participants only made predictions about two return amounts - when the trustee decided how much of $\$ 15$ (based on a $\$ 5$ investment) to return to the trustor, and when the trustee decided how much of $\$ 30$ (based on the full $\$ 10$ investment) to return to the trustor.

Finally, participants received a blank copy of the same social values measure they had completed at the beginning of the study and were asked to predict how their friend had responded 
to each of the nine items. In the interest of time, we did not ask participants to predict a stranger's responses to the social values measure.

After making their predictions, participants were paid the amount that they earned in one (randomly selected) decision scenario, plus a showup fee and any bonuses they earned from correctly predicting others' behaviors. Participants could have earned between $\$ 5$ and $\$ 50$ for participating; the average payment was $\$ 28.89$. The entire study took about 70 minutes. There was no deception.

\section{Study 3 Results}

Two participants were eliminated from the analyses because they misunderstood the instructions and, as a result, either did not complete or completed incorrectly several dependent measures. We also removed these participants' friends from the analyses, assuming that their predictions of these participants' behavior may have been inaccurate due to these misunderstandings. Thus the analyses to follow contain data from 51 dyads, or 102 participants (62 females).

\section{Pre-Study Survey Results}

Table A1 in the online supplement shows that nearly three quarters of participants reported knowing their friend for over one year and that there was a high level of agreement between friends on how long they had known each other, with 81 percent selecting the same category and all others selecting one of the adjacent categories. Further, as shown in Table A2, friends tended to report high levels of closeness to each other. Because the five items designed to measure closeness showed high reliability $(a=0.87)$, we aggregated all items into a single measure of "relational closeness." In addition to showing high agreement on the length of the relationship, friends showed a high level of agreement on the relational closeness scale $(r=0.73, \mathrm{p}<0.001)$.

\section{Gender Effects}

As noted earlier (and as shown in Study 1), gender is a powerful basis for homophily. Consistent with this prior work, 37 (72.5 percent) of the 51 friendship dyads were gender homophilous. The finding is significantly different from chance, $\chi^{2}=20.75, p<0.001$. Thus, if we fail to observe altruism homophily, it cannot be due to the inability of our method to track homophily.

Although we did not find any gender differences in generosity $(t=-0.87, p=0.39)$, we did find gender differences in trust and trustworthiness. Consistent with findings from the trust literature (Buchan, Croson, and Solnick 2008; see also Simpson 2003; Kuwabara 2005), males were more trusting $(M=5.73)$ than females $(M=3.63, t=3.36, p=0.001)$. Males were also marginally, but not significantly, more trustworthy ( $M=6.53$ for males, $M=4.79$ for females, $t=1.57, p=0.12$ ). Thus we control for gender in the analyses to follow.

\section{Homophily Hypotheses}

To address whether friends were homophilous with respect to dispositions, we compare the similarity of behaviors within pairs of friends to that within pairs of strangers. If friends exhibit homophily, participants should be more similar to their friends than to a randomly selected stranger. We created "stranger dyads" by pairing each participant with another randomly selected stranger from his or her laboratory session. For each measure, including number of prosocial responses to the social values measure, generosity, trust, and trustworthiness, we created two scores: the (absolute value) difference between friends' behaviors, and the (absolute value) difference between strangers' behaviors. We then conducted paired sample $t$-tests to examine potential differences in these two scores - specifically, whether the difference between the prosociality of participants and strangers was greater than the difference between the prosociality of participants and their friends. We used this method rather than correlating friends' behaviors because the use of correlation assumes linearity; theoretically, our measures do not meet this assumption.

We begin by looking at whether friends are homophilous with respect to social values and then turn to the three behavioral measures. Table 3 shows the mean differences between friend and stranger dyads for each of the prosociality measures.

Social values: Our measure is the number of altruistic responses (from 0 to 9 ) on the nineitem social values measure. The average abso- 
Table 3: Absolute Differences Between Friends' and Strangers' Respnses for Four Measures of Prosocial Behaviors (Study 3)

\begin{tabular}{lcccccccc}
\hline & \multicolumn{2}{c}{ Social Values } & \multicolumn{2}{c}{ Generosity } & \multicolumn{2}{c}{ Trust } & \multicolumn{2}{c}{ Trustworthiness } \\
Difference: & Mean (SD) & $t$ & Mean (SD) & $t$ & Mean (SD) & $t$ & Mean (SD) & $t$ \\
\hline Stranger Dyads & $4.45(3.34)$ & -1.10 & $4.77(4.04)$ & 1.16 & $3.88(2.79)$ & 0.20 & $0.22(0.16)$ & 0.04 \\
Friend Dyads & $5.06(3.38)$ & & $4.11(4.18)$ & & $3.80(2.90)$ & & $0.22(0.16)$ & \\
\hline
\end{tabular}

Notes: Results from paired-samples $t$-test; for each comparison, $n=51$ dyads. For social values, absolute differences are based on number of prosocial answers on the social values orientation (SVO) scale; possible values range from 0 (no difference) to 9. Absolute differences between friends' and strangers' generosity and trust are measured in dollars. For generosity, possible values range from 0 (no difference) to 20. For trust, possible values range from 0 to 10 . Trustworthiness was weighted and averaged across two measures: amount returned out of 15 dollars and amount returned out of 30 dollars. Possible values for that variable range from 0 to 1 and indicate the difference in the proportion of the endowment that was returned.

lute value difference in the number of prosocial responses between strangers (4.45) on the one hand and friends (5.06) on the other did not differ significantly $(p=0.18)$. In fact, findings trended in the opposite direction than would be expected based on the altruism homophily hypothesis, with strangers being non-significantly more similar than friends. Controlling for gender homophily among friends, as well as for the length of time that the friends had known each other, showed that friends remained as different as strangers in their social values scores $(p=0.57)$. Overall, then, these findings replicate the absence of altruism homophily observed in Studies 1 and 2 .

Behavioral Measures: Consistent with the results from the social values measure, the behavioral measures did not show any significant differences between friend dyads and stranger dyads. Although friends were somewhat more similar than strangers in their levels of generosity (as measured in the dictator game), this difference was not statistically significant $(p=0.18)$. Nor were friends more similar in their levels of trust than pairs of strangers $(p>0.8)$. Perhaps most relevant to the altruism homophily arguments, which often focus on trustworthiness and exploitation of others' cooperation, friends were not more similar than pairs of strangers in their trustworthiness $(p>0.96)$. These findings held when controlling for same-gender pairs and the length of time the friends had known each other. Friends remained as different as strangers in terms of their generosity $(p=0.27)$, trust $(p=0.89)$, and trustworthiness $(p=0.41)$. In short, we do not observe any evidence of homophily for any measure of altruism or prosociality.

\section{Predicting Prosociality}

The results reported thus far reveal no evidence for homophily, but an absence of homophily does not necessarily imply a lack of knowledge of the prosociality of one's friends. This section addresses whether participants can predict their friends' behaviors and, if not, why.

Following prior work (Pradel et al. 2009), we used Kenny and Acitelli's (2001) Actor-Partner Interdependence Model to determine whether participants made accurate predictions of their friends' behavior. The model allows for the simultaneous measurement of predictive accuracy and assumed similarity in dyadic data (Kenny and Acitelli 2001). Because the predictions and behaviors of pairs of friends cannot be considered independent data, we used multilevel modeling with the dyad as the unit of analysis. These models are given in Table 4 .

Outcome variables included predictions of friends' number of prosocial answers on the social values measure (model 1), prediction of friends' generosity in the dictator game (model 2), prediction of friends' trust in the trust dilemma (model 4), and predictions of friends' trustworthiness, weighted and averaged across two variables: amount returned in the trust dilemma with $\$ 15$ and with $\$ 30$ (model 6). The friend's actual behavior in the relevant task and the judge's behavior in that task were included in each model as predictor variables to examine predictive accu- 
Table 4: Estimates from Actor-Partner Interdependence Models Assessing Whether Participants Can Predict Their Friends' Prosociality? (Study 3)

\begin{tabular}{|c|c|c|c|c|c|c|c|}
\hline \multirow[b]{2}{*}{ Intercept } & \multirow{2}{*}{$\begin{array}{c}\text { Social } \\
\text { Values }\end{array}$} & \multicolumn{2}{|c|}{ —Generosity- } & \multicolumn{2}{|c|}{$\longrightarrow$ Trust -} & \multicolumn{2}{|c|}{ Trustworthiness } \\
\hline & & $\begin{array}{c}4.48 \\
(2.56)\end{array}$ & $\begin{array}{c}2.37 \\
(2.35)\end{array}$ & $\begin{array}{c}1.23 \\
(1.68)\end{array}$ & $\begin{array}{c}-1.04 \\
(1.35)\end{array}$ & $\begin{array}{c}-0.29 \\
(0.23)\end{array}$ & $\begin{array}{c}-0.36 \\
(0.22)\end{array}$ \\
\hline Friend's Actual Behavior & $\begin{array}{c}0.11 \\
(0.09)\end{array}$ & $\begin{array}{c}0.04 \\
(0.08)\end{array}$ & $\begin{array}{c}0.12^{\dagger} \\
(0.07)\end{array}$ & $\begin{array}{c}0.05 \\
(0.08)\end{array}$ & $\begin{array}{c}0.07 \\
(0.06)\end{array}$ & $\begin{array}{c}0.08 \\
(0.08)\end{array}$ & $\begin{array}{c}0.09 \\
(0.08)\end{array}$ \\
\hline Judge's Actual Behavior & $\begin{array}{c}0.61^{\dagger} \\
(0.10)\end{array}$ & $\begin{array}{c}0.51^{\dagger} \\
(0.08)\end{array}$ & $\begin{array}{r}0.29^{\dagger} \\
(0.08)\end{array}$ & $\begin{array}{r}0.69^{\dagger} \\
(0.08)\end{array}$ & $\begin{array}{r}0.39^{\dagger} \\
(0.08)\end{array}$ & $\begin{array}{r}0.82^{\dagger} \\
(0.08)\end{array}$ & $\begin{array}{r}0.70^{\dagger} \\
(0.09)\end{array}$ \\
\hline Predicted Stranger's Behavior & & & $\begin{array}{r}0.48^{\dagger} \\
(0.08)\end{array}$ & & $\begin{array}{c}0.64^{\dagger} \\
(0.10)\end{array}$ & & $\begin{array}{r}0.25^{\dagger} \\
(0.09)\end{array}$ \\
\hline Male & $\begin{array}{c}0.41 \\
(0.75)\end{array}$ & $\begin{array}{c}0.41 \\
(0.79)\end{array}$ & $\begin{array}{c}-0.03 \\
(0.67)\end{array}$ & $\begin{array}{c}0.56 \\
(0.52)\end{array}$ & $\begin{array}{c}0.01 \\
(0.45)\end{array}$ & $\begin{array}{c}0.09 \\
(0.06)\end{array}$ & $\begin{array}{c}0.08 \\
(0.06)\end{array}$ \\
\hline Male Friend & $\begin{array}{r}-1.78^{*} \\
(0.75)\end{array}$ & $\begin{array}{r}-2.35^{\dagger} \\
(0.78)\end{array}$ & $\begin{array}{r}-2.39^{\dagger} \\
(0.65)\end{array}$ & $\begin{array}{c}-0.54 \\
(0.52)\end{array}$ & $\begin{array}{c}-0.67 \\
(0.44)\end{array}$ & $\begin{array}{c}-0.07 \\
(0.06)\end{array}$ & $\begin{array}{c}-0.07 \\
(0.06)\end{array}$ \\
\hline Relational Closeness & $\begin{array}{c}0.09 \\
(0.07)\end{array}$ & $\begin{array}{c}-0.07 \\
(0.07)\end{array}$ & $\begin{array}{c}-0.07 \\
(0.06)\end{array}$ & $\begin{array}{c}-0.01 \\
(0.05)\end{array}$ & $\begin{array}{c}0.03 \\
(0.04)\end{array}$ & $\begin{array}{c}0.01^{*} \\
(0.01)\end{array}$ & $\begin{array}{r}0.01^{*} \\
(0.01)\end{array}$ \\
\hline Known at Least One Year & $\begin{array}{c}0.25 \\
(0.71)\end{array}$ & $\begin{array}{c}0.41 \\
(0.75)\end{array}$ & $\begin{array}{c}0.55 \\
(0.67)\end{array}$ & $\begin{array}{c}-0.16 \\
(0.53)\end{array}$ & $\begin{array}{c}0.19 \\
(0.41)\end{array}$ & $\begin{array}{c}0.00 \\
(0.06)\end{array}$ & $\begin{array}{c}-0.01 \\
(0.06)\end{array}$ \\
\hline
\end{tabular}

Notes: The outcome variable for each model is the judge's prediction of friend's social values, generosity, trust, or trustworthiness, respectively. Analyses for each model were based on $n=102$ individuals nested in $n=51$ dyads.

${ }^{*} p<0.01 ; \dagger p<0.05$.

racy and assumed similarity effects, respectively. Following related work (Pradel et al. 2009), we used predictions of friends' behaviors as outcome variables (rather than independent variables) and friends' actual behaviors as independent variables (rather than outcome variables), because the argument about detecting telltale signs of disposition posits that a person's behavior impacts another's predictions of her behavior.

We also included several control variables in each model: length of the friendship, relational closeness, gender of judge, and gender of target. An additional control variable, prediction of stranger's behavior, was added to models 3,5 , and 7. As explained below, this control variable allows us to measure whether the projection of one's own behavior onto friends occurs above and beyond baseline projection effects.

Results show that predictions of friends' behaviors were strongly impacted by assumed similarity or perceived homophily: judges tended to predict that their friends' behavior was similar to their own. The actual behavior of targets, however, was unrelated to these predictions. Models 1 (for social values), 2 (generosity), 4 (trust), and
6 (trustworthiness) show that judges consistently projected their own dispositions and behaviors onto their friends (all $p<0.001$ ). Further, for all measures, targets' actual behaviors were unrelated to those predictions (all $p>0.24$ ). Thus the hypothesis that people can accurately predict their friends' prosocial behaviors was not supported; rather, as expected, participants tended to predict that their friends would behave as they did, even though, as shown earlier, they did not 5

One possible explanation for judges' projection of their own behavior onto their friends' is that judges tend to use their own behavior as an anchor, projecting their own behaviors onto everyone, whether friends or strangers (Orbell and Dawes 1993). Controlling for baseline pro-

\footnotetext{
${ }^{5}$ We assessed the predictive accuracy of friends' behaviors via a number of other methods. For instance, we looked at the (absolute value) difference between predicted and actual behavior for friends and the (absolute value) difference between predicted and actual behavior for strangers for all our behavioral measures of prosociality. These analyses, available upon request, yielded substantively identical conclusions to those just reported. We did not find any evidence that people can accurately predict their friend's behavior better than a stranger's.
} 
jection may therefore increase the chances that we find support for the ability of participants to predict their friends' prosociality. Models 3, 5 , and 7 include a control for targets' predictions of strangers' behaviors. (Participants did not predict strangers' responses to the social values measure; thus we drop this measure from further consideration.) As these models show, targets' predictions of strangers' generosity, trust, and trustworthiness were significantly related to predictions of friends' respective behaviors (all $p<0.05$ ). However, the perceived homophily effect remained highly significant in each model (all $p<0.001)$. That is, predictions for friends were strongly influenced by the judges' own behavior, even after controlling for baseline projection tendencies (i.e., predictions for strangers). Predictive accuracy remained non-significant after controlling for predictions for strangers. There was only a weak trend for the generosity measure $(p=0.10$, all others $p>0.3)$.

We also tested another (non-competing) explanation for the poor predictions of friends' behaviors. People may assume that their friend's behavior within the relation is caused by the friend's disposition rather than by relational demands. This would lead participants to predict that their friends are more altruistic than strangers. We found limited support for this argument. Paired sample $t$-tests show that participants rated their friends as being (marginally) more generous $(t=1.79, p=0.076)$, more trusting $(t=2.73, p=0.007)$, and (marginally) more trustworthy $(t=1.68, p=0.097)$ than strangers. Analyses that controlled for the judge's and friend's genders showed somewhat stronger effects for generosity $(t=3.97, p<0.001)$ and comparable effects for trust $(t=2.64, p=0.01)$. The effects for trustworthiness became weaker $(t=1.37, p=0.17){ }^{6}$

Summing up, the hypothesis that people can accurately predict their friends' behavior was

\footnotetext{
${ }^{6}$ While participants tended to predict that their friends were more altruistic than strangers, they expected that their friends would be less altruistic than they themselves were. Comparing participants' own behaviors to their predictions of their friends' behaviors, participants predicted their friends would be less generous $(t=-2.20, p=0.03)$ trusting $(t=-1.83, p=0.07)$ and trustworthy $(t=-2.81$, $p=.006)$. These findings suggest that the "uniqueness bias" (Goethals et al. 1991), or the tendency to believe that one is particularly moral or prosocial, may also cloud perceptions of friends' dispositions.
}

not supported. Across a variety of measures, participants had remarkably poor insight into their friends' dispositions. Our results point to a key mechanism underlying this lack of insight. As expected, friendships were characterized by perceived homophily, or the tendency for people to falsely assume that their friends are more similar to them than they actually are.

\section{Discussion}

The findings from Study 3, which used multiple costly behavioral measures, are highly consistent with findings from Studies 1 and 2. In no study did we find compelling evidence of altruism homophily for any of the measures. This increases our confidence that the findings of the absence of homophily in Studies 1 and 2 were not driven by measurement issues. Results from all three studies stand in sharp contrast to a key prediction from some evolutionary models of altruism: that altruism homophily should emerge out of the ability and motivation of humans to read telltale signs of disposition in prospective partners, and to form relationships on those bases.

Note, however, that even if we had found evidence of dispositional homophily, it need not have implied that relationships emerge out of the altruist detection processes assumed in altruism homophily approaches. Dispositional homophily might instead result from the tendency for those with similar dispositions to be disproportionately exposed to one another (Blau 1977b; McPherson et al. 2001).7 For instance, prior work shows that altruists are more likely to contribute to charities (Van Lange et al. 2007). By extension, they may be more prevalent in groups devoted to prosocial causes 8 If so, given the critical

\footnotetext{
${ }^{7}$ It could also stem from influence processes, or the tendency for friends to develop more similar dispositions and values over time (e.g., Mark 2002). Thus, the spread of altruism (or egoism) from one friend to another could lead to homophily.

${ }^{8}$ Indeed, a failure to observe a higher proportion of altruists in more prosocial groups would constitute a blow to the altruism measure we used in the three studies reported earlier. As a check on this, we administered the same social values survey to a service sorority on the same campus as the traditional sorority used in Study 2. Of the 48 service sorority sisters who completed the survey, four could not be classified due to inconsistent choices. Of the remaining 44, 72 percent (32) were classified as altruists, with the remaining 12 either competitors or individualists
} 
role that propinquity plays in friendship formation (e.g., Festinger, Schachter, and Back 1950; Feld 1982), we might expect to observe dispositional homophily as a result of this sorting process. Thus, the fact that we did not observe altruism homophily may be surprising not only from the altruist detection perspective, but also - at least, at first glance - from a social structural one.

Although dispositions may influence membership in some types of organizations (as suggested by our comparison of the service and traditional sororities; see note 8), prior work suggests that sociodemographic dimensions such as ethnicity, gender, age, religion, education, and occupational status are far more common bases of homogeneity within organizations than are values or dispositions (McPherson et al. 2001). As a result, these are the sociodemographic dimensions along which we typically observe homophily. Because these sociodemographic characteristics are largely orthogonal to dispositional altruism (see, for example, Batson et al. 1989; Orbell et al. 1994; Simpson et al. 2007), it is not surprising that prevailing bases of organizational memberships do not generally lead to dispositional homophily.

In addition to the absence of dispositional homophily, we found no support for the hypothesis that people can intuit their friends' altruism or egoism (Frank 2005). Across a variety of measures, participants were no better at predicting the dispositions of their friends than of strangers they did not meet.

A series of ancillary studies described earlier (and available upon request) help reconcile the absence of homophily and poor insight into friends' dispositions with results from prior work showing that people can read telltale signs in strangers. Those ancillary studies found that people consider others' dispositions less important in repeated interactions than in one-off interactions and are less willing to invest resources to discern another's disposition when they anticipate repeated versus one-off interactions. If people consider others' dispositions relatively inconsequential in repeated interactions, altruist detection should play a smaller role in relation-

(egoists). As noted in our discussion of Study 2, among the members of the traditional sorority who could be classified, just under half (48 percent) were prosocial and those remaining were egoists. This difference is significant $\left(\chi^{2}=7.59, p=0.006\right.$, suggesting that more prosocial groups may contain a higher proportion of altruists. ship formation than suggested by prior work. As a consequence, there is little reason to expect altruism homophily in relationships. Data from all three studies support the predicted absence of altruism homophily. Moreover, we argued that, even though friendships are relatively random with respect to dispositions, people will perceive their friends to be as altruistic or egoistic as they themselves are. Consistent with this argument, Study 3 established strong evidence of perceived homophily (McPherson et al. 2001; Goel, Mason, and Watts 2010), with friends believing that they were much more similar to each other in their levels of altruism (or egoism) than they actually were.

These findings cast additional light on Granovetter's (1985) assertion that economic activity is "embedded" in ongoing social relations. Altruist detection arguments resemble "over socialized" models wherein individuals consistently exhibit cooperative or egoistic behavioral preferences, and exchange decisions are based on detecting these inclinations. In contrast, pure reciprocity approaches are analogous to "under socialized" models, where actors exchange using a tit-fortat strategy but do not vary in their altruistic preferences. A more accurate view is that humans employ "embedded" strategies rather than either of these alternatives; there is very good evidence that humans differ in their inclinations towards altruism and egoism, but there is equally good evidence that these inclinations are modified by the structure of the relationships over which exchanges occur. Moreover, our ancillary studies found that people anticipate changes in partner behavior based on the nature of the relationship, and are willing to invest more in assessing a prospective partner's character when the structure of the relationship does not encourage good behavior. Thus, not only is trust a heuristic (Uzzi 1997), but a heuristic that helps to determine whom one should trust, enabling cooperation even between actors who are otherwise rivals (e.g. Ingram and Roberts 2000).

\section{Conclusion}

A longstanding puzzle in the social and biological sciences is the emergence and persistence of altruism. This puzzle is underscored by the recent 
proliferation of findings on heterogeneous social preferences; even in our own highly cooperative species, individuals vary considerably in the extent to which they are altruistic. The ability of altruists to find and selectively sort with one another into ongoing relations has been a prominent explanation for the persistence of altruism in the midst of this heterogeneity (Frank 1988; Macy and Skvoretz 1998; Brown et al. 2003; Boone and Buck 2003; Feinberg, Willer, and Keltner 2012). We have argued that we should not expect such sorting, despite people's demonstrated ability to detect altruism in others. Multiple studies using several different analytical strategies converged on the same conclusion: friendships are not characterized by greater than chance levels of altruism homophily.

At one level, our arguments and findings challenge the relevance of altruism homophily arguments. These arguments hinge on altruists' tendencies to find and form relations with one another in order to reap the benefits of cooperation, but we found no evidence of such sorting. Nor did we find any evidence that friends could discern each other's dispositions; instead, they tended to perceive altruism homophily where it did not exist. This would seem to suggest that human altruism must emerge and persist by some process other than the one posited in altruism homophily arguments.

But consideration of our findings alongside results from our ancillary studies and prior work support a different takeaway; when they anticipate repeated interaction, people will be less concerned about others' altruism or egoism and are unlikely to invest the resources necessary to try to discern prospective partners' dispositions. Instead, they proceed cautiously through the early stages of relationships, assuming that the logic of reciprocity will tend to keep egoists' opportunism in check. In situations where repeated interactions can be expected, and therefore opportunistic behavior can be punished in the future, an exchange partner's disposition is less relevant. Yet sometimes people do expect-accurately or not - one-off interactions, and our results suggest that it is under these conditions that people should be most concerned about others' dispositions.

It follows from the foregoing that the relative importance of altruist detection processes to the emergence and persistence of altruism depends on the frequency of one-off interactions. For instance, one-off interactions will be more prevalent when social mobility is high (Macy and Sato 2002). When mobility is relatively low, and most interactions are embedded in ongoing relations, people will simply rely on the logic of reciprocity. Conversely, and consistent with simulation models (Macy and Sato 2002), increases in social mobility and the frequency of one-off interactions may lead to increased efforts to discern others' dispositions $9^{9}$ By extension, if the capacity to read telltale signs of altruism increases with experience, as some research suggests (Yamagishi et al. 1999), we should expect detection abilities to vary with the prevalence of social mobility and other conditions, giving rise to more frequent oneoff interactions. Thus, it is in those settings where the future does not cast a long shadow that we might expect people to be most concerned about and thus more apt to invest in discerning others' dispositions, and where we should most expect to observe altruism homophily. Viewed in this way, our research builds a sociological bridge between altruist detection approaches and reciprocity arguments, two fundamental approaches to prosociality that otherwise appear contradictory or, at best, independent.

\section{References}

Axelrod, Robert. 1984. The Evolution of Cooperation. New York: Basic Books.

Barrera, Davide. 2007. "The Impact of Negotiated Exchanges on Trust and Trustworthiness". Social Networks 29:508-526. http://dx.doi.org/10.1016/j.socnet. 2007.03 .004 .

Batson, C. Daniel, Kathryn C. Oleson, Joy L. Weeks, Sean P. Healy, Penny J. Reeves, Patrick Jennings, and Thomas Brown. 1989. "Religious Prosocial Motivation: Is it Altruistic or Egoistic?" Journal of Personality and Social Psychology 57:873-884. http://dx doi.org/10.1037/0022-3514.57.5.873

\footnotetext{
${ }^{9}$ Yet, as noted by Macy and Sato (2002), if social mobility is very high, population-level trustworthiness may drop so low as to make investment in discerning telltale signs not worth the cost or effort.
} 
Berg, Joyce, John Dickhaut, and Kevin McCabe. 1995. "Trust, Reciprocity, and Social History." Games and Economic Behavior 10:122-142. http://dx.doi.org/10.1006/ game.1995.1027.

Blau, Peter M. 1977a. Inequality and Heterogeneity: A Primitive Theory of Social Structure. New York: The Free Press.

_ 1977b. "A Macrosociological Theory of Social Structure." American Journal of Sociology 83:26-54. http://dx.doi.org/10.1086/ 226505.

Bogaert, Sandy, Christophe Boone, and Carolyn Declerck. 2008. "Social Value Orientation and Cooperation in Social Dilemmas: A Review and Conceptual Model." British Journal of Social Psychology 47:453-480. http://dx doi.org/10.1348/014466607X244970.

Boone, R. Thomas, and Ross Buck. 2003. "Emotional Expressivity and Trustworthiness: The Role of Nonverbal Behavior in the Evolution of Cooperation." Journal of Nonverbal Behavior 27: 163-182. http://dx.doi.org/10 1023/A:1025341931128.

Brosig, Jeannette. 2002. "Identifying Cooperative Behavior: Some Experimental Results in a Prisoner's Dilemma Game." Journal of Economic Behavior and Organization 47:275-290. http://dx.doi.org/10.1016/ S0167-2681(01)00211-6.

Brown, William Michael, Boris Palameta, and Chris Moore. 2003. "Are There Nonverbal Cues to Commitment? An Exploratory Study Using the Zero-Acquaintance Video Presentation Paradigm." Evolutionary Psychology 1:42-69.

Buchan, Nancy R., Rachel T. A. Croson, and Sara Solnick. 2008. "Trust and Gender: An Examination of Behavior, Biases, and Beliefs in the Investment Game." Journal of Economic Behavior and Organization 68:46676. http://dx.doi.org/10.1016/j.jebo 2007.10 .006

Carley, Kathleen. 1991. "A Theory of Group Stability." American Sociological Review 56:331-354. http://dx.doi.org/10.2307/ 2096108.

Dawkins, Richard. 1976. The Selfish Gene. Oxford: Oxford University Press.
Emonds, Griet, Carolyn H. Declerck, Christophe Boone, Everhard J. M. Vandervliet, and Paul M. Parizel. 2011. "Comparing the Neural Basis of Decision Making in Social Dilemmas of People with Different Social Value Orientations, a fMRI Study." Journal of Neuroscience, Psychology, and Economics 4:11-24. http://dx.doi.org/10.1037/a0020151.

Eshel, Ilan and L. L. Cavalli-Sforza. 1982. "Assortment of Encounters and Evolution of Cooperativeness." Proceedings of the National Academy of Sciences 79:1331-1335. http: //dx.doi.org/10.1073/pnas.79.4.1331.

Fehr, Ernst and Herbert Gintis 2007. "Human Motivation and Social Cooperation: Experimental and Analytical Foundations." Annual Review of Sociology 33:43-64. http://dx.doi.org/10.1146/annurev . soc.33.040406.131812.

Feinberg, Matthew, Robb Willer, and Dacher Keltner. 2012a. "Flustered and Faithful: Embarrassment as a Signal of Prosociality." Journal of Personality and Social Psychology 102:81-97. http://dx.doi.org/10.1037/ a0025403.

Feld, Scott. 1981. "The Focused Organization of Social Ties." American Journal of Sociology, 86:1015-1035. http://dx.doi.org/10 $1086 / 227352$.

. 1982. "Social Structural Determinants of Similarity among Associates." American Sociological Review 47:797-801. http://dx doi.org/10.2307/2095216.

Festinger, Leon, Stanley Schachter, and Kurt Back. 1950. "The Spatial Ecology of Group Formation." Pp. 141-161 in Social Pressure in Informal Groups, edited by L. Festinger, S. Schachter, and K. Back. Stanford, CA: Stanford University Press.

Fetchenhauer, Detlef, Ton Groothuis, and Julia Pradel. 2010. "Not Only States but Traits: Humans can Identify Permanent Altruistic Dispositions in 20 Seconds." Evolution and Human Behavior 31:80-86. http://dx.doi.org/10.1016/j evolhumbehav.2009.06.009.

Frank, Robert H. 1988. Passions within Reason: The Strategic Role of the Emotions. New York: W. W. Norton \& Company. 
2005. "Altruists with Green Beards: Stick Kicking?" Analyse 85 Kritik 27:85-96.

Frank, Robert H., Thomas Gilovich, and Dennis T. Regan. 1993. "The Evolution of OneShot Cooperation: An Experiment." Ethology and Sociobiology 14:247-256. http://dx.doi org/10.1016/0162-3095(93) 90020-I.

Goel, Sharad, Winter Mason, and Duncan J. Watts. 2010. "Real and Perceived Attitude Agreement in Social Networks." Journal of Personality and Social Psychology 99:611-21. http://dx.doi.org/10.1037/a0020697.

Goethals, George R., David M. Messick, and Scott T. Allison. 1991. "The Uniqueness Bias." Pp. 149-76 in Social Comparison: Contemporary Theory and Research, edited by J. Suls and T. A. Wills. Hillsdale, NJ: Lawrence Erlbaum Associates.

Gouldner, Alvin W. 1960. "The Norm of Reciprocity: A Preliminary Statement." American Sociological Review 25:161-78. http: //dx.doi.org/10.2307/2092623.

Granovetter, Mark. 1985. "Economic Action and Social Structure: The Problem of Embeddedness." The American Journal of Sociology 91:481-510. http://dx.doi.org/10.1086/ 228311.

Harbaugh, William and Kate Krause. 2000. "Children's Altruism in Public Good and Dictator Experiments." Economic Inquiry 38:95109. http://dx.doi.org/10.1093/ei/38 1.95

Heckathorn, Douglas D. 2007. "Extensions of Respondent-Driven Sampling: Analyzing Continuous Variables and Controlling for Differential Recruitment." Sociological Methodology 37:151-207. http://dx.doi.org/10.1111/ j.1467-9531.2007.00188.x.

Hoffman, Elizabeth, Kevin McCabe, and Vernon L. Smith. 1996. "Social Distance and OtherRegarding Behavior in Dictator Games." The American Economic Review 86:653-680.

Huston, Ted L. and George Levinger. 1978. "Interpersonal Attraction and Relationships." Annual Review of Psychology 29:115-156. http://dx.doi.org/10.1146/annurev.ps. 29.020178.000555

Ingram, Paul and Peter W. Roberts. 2000. "Friendship among Competitors in the Syd- ney Hotel Industry." The American Journal of Sociology 106: 387-423. http://dx.doi org/10.1086/316965

Kelley, Harold H. and John W. Thibaut. 1978. Interpersonal Relations: A Theory of Interdependence. Hoboken, NJ: John Wiley \& Sons Inc.

Kenny, David A. and Linda K. Acitelli. 2001. "Accuracy and Bias in the Perception of the Partner in a Close Relationship." Journal of Personality and Social Psychology 80:439-448. http://dx.doi.org/10.1037/ 0022-3514.80.3.439

Kollock, Peter. 1998. "Social Dilemmas: The Anatomy of Cooperation." Annual Review of Sociology 24:183-214. http://dx.doi.org/ 10.1146/annurev.soc.24.1.183

Kuhlman, Daniel and Alfred Marshello. 1975. "Individual Differences in the Game Motives of Own, Relative, and Joint Gain." Journal of Research in Personality 9:240-251. http://dx.doi.org/10.1016/ 0092-6566(75) 90020-3.

Kuwabara, Ko. 2005. "Nothing to Fear but Fear Itself: Fear of Fear, Fear of Greed, and Gender Effects in Two-Person Asymmetric Social Dilemmas." Social Forces 84:1257-72. http: //dx.doi.org/10.1353/sof.2006.0020

Lazarsfeld, Paul F. and Robert K. Merton. 1954. "Friendship as a Social Process: A Substantive and Methodological Analysis." Freedom and Control in Modern Society 18:18-66.

Liebrand, Wim B. G. 1986. "The Ubiquity of Social Values in Social Dilemmas." Pp. 113-133 in Experimental Studies of Social Dilemmas, edited by Henk Wilke, Christel Rutte, and David Messick. Frankfurt: Peter Lang Publishing Company.

Lusher, Dean, Johan Koskinen, and Garry Robins. 2013. Exponential Random Graph Models for Social Networks: Theory, Methods, and Applications. New York, NY: Cambridge University Press.

Macy, Michael W. and Yoshimichi Sato. 2002. "Trust, Cooperation, and Market Formation in the U.S. and Japan." Proceedings of the $\mathrm{Na}$ tional Academy of Sciences 99:7214-20. http: //dx.doi.org/10.1073/pnas.082097399 
Macy, Michael W. and John Skvoretz. 1998. "The Evolution of Trust and Cooperation between Strangers: A Computational Model." American Sociological Review 63:638-660. http: //dx.doi.org/10.2307/2657332.

Mark, Noah. 1998. "Birds of a Feather Sing Together." Social Forces 77: 453-485. http: //dx.doi.org/10.1093/sf/77.2.453.

Mark, Noah P. 2002. "Cultural Transmission, Disproportionate Prior Exposure, and the Evolution of Cooperation." American Sociological Review 67:323-344. http://dx.doi.org/10 $2307 / 3088960$

Marsden, Peter V. and Karen E. Campbell. 1984. "Measuring Tie Strength." Social Forces 63:482-501. http://dx.doi.org/10.1093/ sf $/ 63.2 .482$

Mayhew, Bruce, Miller McPherson, Tom Rotolo, and Lynn Smith-Lovin. 1995. "Sex and Ethnic Heterogeneity in Face-to-Face Groups in Public Places: An Ecological Perspective on Social Interaction." Social Forces 74:15-52. http://dx.doi.org/10.1093/sf/74.1.15

McPherson, Miller, Lynn Smith-Lovin, and James M Cook. 2001. "Birds of a Feather: Homophily in Social Networks." Annual Review of Sociology 27:415-444. http://dx doi.org/10.1146/annurev.soc.27.1.415

Messick, David M. and Charles G McClintock. 1968. "Motivational Bases of Choice in Experimental Games." Journal of Experimental Social Psychology 4:1-25. http://dx.doi.org/ 10.1016/0022-1031(68)90046-2.

Oda, Ryo, Noriko Yamagata, Yuki Yabiku, and Akiko Matsumoto-Oda. 2009. "Altruism Can Be Assessed Correctly Based on Impression." Human Nature 20(3):331-341. http://dx doi.org/10.1007/s12110-009-9070-8.

Orbell, John M. and Robyn M. Dawes. 1993. "Social Welfare, Cooperators' Advantage, and the Option of Not Playing the Game." American Sociological Review 58:787. http://dx doi.org/10.2307/2095951.

Orbell, John, Robyn M. Dawes, and Peregrine Schwartz-Shea. 1994. "Trust, Social Categories, and Individuals: The Case of Gender." Motivation and Emotion 18:109-128. http://dx.doi.org/10.1007/BF02249396

Parks, Craig D. and Ann C. Rumble. 2001. "Elements of Reciprocity and Social Value Orientation." Personality and Social Psychology Bulletin 27:1301-1309. http://dx.doi.org/ 10.1177/01461672012710006.

Paxton, Pamela and James Moody. 2003. "Structure and Sentiment: Explaining Emotional Attachment to Group." Social Psychology Quarterly 66:34-47. http://dx.doi.org/10 2307/3090139.

Piliavin, Jane Allyn and Hong-Wen Charng. 1990. "Altruism: A Review of Recent Theory and Research." Annual Review of Sociology 16:2765. http://dx.doi.org/10.1146/annurev so.16.080190.000331.

Pradel, Julia, Harald A. Euler, and Detlef Fetchenhauer. 2009. "Spotting Altruistic Dictator Game Players and Mingling With Them: The Elective Assortation of Classmates." Evolution and Human Behavior 30:103-113. http://dx.doi.org/10.1016/ j.evolhumbehav.2008.09.003.

Rand David G. and Martin A. Nowak. 2013. "Human Cooperation." Trends in Cognitive Sciences 17:413-25. http://dx.doi.org/10 1016/j.tics.2013.06.003

Robson, Arthur J. 1990. "Efficiency in Evolutionary Games: Darwin, Nash and the Secret Hand- shake." Journal of Theoretical Biology 144:379-96. http://dx.doi.org/10.1016/ S0022-5193(05) 80082-7.

Rusbult, Caryl E. and Paul A. M. Van Lange. 2003. "Interdependence, Interaction, and Relationships." Annual Review of Psychology 54:351-75. http://dx.doi.org/10.1146/ annurev.psych.54.101601.145059.

Scott, Marvin B. and Stanford M. Lyman. 1968. "Accounts." American Sociological Review 33:46-62. http://dx.doi.org/10 2307/2092239.

Sheldon, Kennon M., Melanie Skaggs Sheldon, and Richard Osbaldiston. 2000. "Prosocial Values and Group Assortation." Human Nature 11:387-404. http://dx.doi.org/10 1007/s12110-000-1009-z

Simpson, Brent. 2003. "Sex, Fear and Greed: A Social Dilemma Analysis of Gender and Cooperation." Social Forces 82:35-52. http: //dx.doi.org/10.1353/sof.2003.0081. 
Simpson, Brent, Tucker McGrimmon, and Kyle Irwin. 2007. "Are Blacks Really Less Trusting than Whites? Revisiting the Race and Trust Question." Social Forces 86:526-552. http: //dx.doi.org/10.1093/sf/86.2.525.

Simpson, Brent and Robb Willer. 2008. "Altruism and Indirect Reciprocity: The Interaction of Person and Situation in Prosocial Behavior." Social Psychology Quarterly 71:37-52. http://dx.doi.org/10.1177/ 019027250807100106

Smith, Jeffrey A., Miller McPherson, and Lynn Smith-Lovin. 2014. "Social Distance in the United States: Sex, Race, Religion, Age, and Education." American Sociological Review 79:432-456. http://dx.doi.org/10.1177/ 0003122414531776 .

Sober, Elliott and David Sloan Wilson. 1998. Unto Others: The Evolution and Psychology of Unselfish Behavior. Cambridge, MA: Harvard University Press.

Trivers, Robert L. 1971. "The Evolution of Reciprocal Altruism." The Quarterly Review of Biology 46(1):35-57. http://dx.doi.org/ 10.1086/406755.

Uzzi, Brian. 1997. "Social Structure and Competition in Interfirm Networks: The Paradox of Embeddedness." Administrative Science Quarterly 42:35-67. http://dx.doi.org/10 2307/2393808

Van Lange, Paul A. M. 1999. "The Pursuit of Joint Outcomes and Equality in Outcomes: An Integrative Model of Social Value Orientation." Journal of Personality and Social Psychology 77:337-349. http://dx.doi.org/10 1037/0022-3514.77.2.337.

Van Lange, Paul A. M., Christopher Agnew, Fieke Harinck, and Gemma E. M. Steemers. 1997. "From Game Theory to Real Life: How Social Value Orientation Affects Willingness to Sacrifice in Ongoing Close Relationships." Journal of Personality and Social Psychology 73:1330-44. http://dx.doi.org/10.1037/ 0022-3514.73.6.1330

Van Lange, Paul A. M., Rene Bekkers, Theo N. M. Schuyt, and Mark Van Vugt. 2007. "From Games to Giving: Social Value Orientation Predicts Donations to Nobel Causes." Basic and Applied Social Psychology
29:375-384. http://dx.doi.org/10.1080/ 01973530701665223.

Van Lange, Paul A. M., Anthon Klapwijk, and Laura M. Van Munster. 2011. "How the Shadow of the Future might Promote Cooperation." Group Processes 6 Intergroup Relations 14:857-70. http://dx.doi.org/10 1177/1368430211402102

Verplaetse, Jan, Sven Vanneste, and Johan Braeckman. 2007. "You Can Judge a Book by its Cover: The Sequel. A Kernel of Truth in Predictive Cheating Detection." Evolution and Human Behavior 28:260-271. http://dx.doi.org/10.1016/ j.evolhumbehav.2007.04.006.

Wejnert, Cyprian. 2010. "Social Network Analysis with Respondent-Driven Sampling Data: a Study of Racial Integration on Campus." Social Networks 32:112-124. http://dx.doi org $/ 10.1016 /$ j.socnet.2009.09.002.

Willer, Robb, Matthew Feinberg, Francis J. Flynn, and Brent Simpson. 2014. "The Duality of Generosity: Altruism and Status Seeking Motivate Prosocial Behavior." Working Paper.

Wilson, David Sloan and Lee A. Dugatkin. 1997. "Group Selection and Assortative Interactions." The American Naturalist 149:336. http://dx doi.org/10.1086/285993

Yamagishi, Toshio, Masako Kikuchi, and Motoko Kosugi. 1999. "Trust, Gullibility, and Social Intelligence." Asian Journal of Social Psychology 2:145-161. http://dx.doi.org/10 1111/1467-839X.00030.

Yamagishi, Toshio, Shigehito Tanida, Rie Mashima, Eri Shimoma, and Satoshi Kanazawa. 2003. "You Can Judge a Book by its Cover: Evidence that Cheaters may Look Different from Cooperators." Evolution and Human Behavior 24:290-301. http://dx.doi.org/10.1016/ S1090-5138(03) 00035-7. 
Acknowledgements: We thank Cyprian Wejnert for giving us access to the data used in Study 1 and Hanne van der Iest for helpful comments and suggestions on previous drafts. This research was supported by grants SES-0647169 and SES1058236 from the National Science Foundation.

Brent Simpson: University of South Carolina. E-mail: bts@sc.edu.

Matthew Brashears: Cornell University.

E-mail: meb299@cornell.edu.

Eric Gladstone: Cornell University.

E-mail: eg366@cornell.edu.

Ashley Harrell: University of South Carolina. E-mail: harrella@mailbox.sc.edu. 